\title{
Balanço de Emissões e Remoções de Gases de Efeito Estufa no Campus da Universidade Federal de Viçosa
}

\author{
Daniel Brianezi ${ }^{1}$, Laércio Antônio Gonçalves Jacovine ${ }^{1}$, \\ Carlos Pedro Boechat Soares ${ }^{1}$, Wantuelfer Gonçalves ${ }^{1}$, \\ Samuel José Silva Soares da Rocha ${ }^{1}$
}

${ }^{1}$ Departamento de Engenharia Florestal, Universidade Federal de Viçosa - UFV, Viçosa/MG, Brasil

\begin{abstract}
RESUMO
Objetivou-se com este estudo realizar o balanço das emissões e remoções de Gases de Efeito Estufa (GEE) do campus-sede da Universidade Federal de Viçosa - UFV (Viçosa, MG), comparando a emissão de GEE do ano-base adotado (outubro de 2010 a outubro de 2011) e o incremento médio anual de carbono pelos sumidouros da universidade (arborização urbana, florestas nativas e plantadas). Utilizou-se dados coletados na universidade e metodologias da ABNT NBR ISO 14064 e do IPCC. Os resultados encontrados apontaram que o campus-sede da UFV possui uma grande cobertura vegetal que representam 39,84\% de sua área total. No entanto, estas áreas não foram suficientes para compensar as $6.034,18 \mathrm{tCO}_{\text {2eq. }}$ emitidas pela universidade. Portanto, o balanço geral das emissões e remoções de GEE do campus-sede da UFV foi negativo (déficit de 727,02 $\mathrm{tCO}_{2 \mathrm{eq} .}$ ). Embora tenha apresentado este resultado, os sumidouros de carbono foram importantes para a compensação de parte dos GEE gerados.
\end{abstract}

Palavras-chave: florestas urbanas, emissão e remoção de gases, neutralização, balanço rural e urbano.

\section{Balance of Emissions and Removals of Greenhouse Gases at Campus of Universidade Federal de Viçosa}

\begin{abstract}
The objective of this study was to generate the balance of Greenhouse Gases (GHG) emissions and removals at main campus of Universidade Federal de Viçosa - UFV (Viçosa, MG), contrasting GHG emissions in base-year (October 2010 to October 2011) and the annual average carbon increment of university sinks (urban trees, native and planted forests). We used data collected at university, and ABNT NBR ISO 14064 and IPCC database. The final results indicated that main campus of UFV own huge forest field that represents $39.84 \%$ overall. However, these areas were not enough to compensate $6,034.18 \mathrm{tCO}_{2 \mathrm{eq}}$ released of the university. Therefore, the global GHG emissions and removals at main campus of UFV was negative (727.02 $\mathrm{tCO}_{2 \mathrm{eq}}$ of shortfall). Although this result, carbon sinks were important to offset part of GHG generated.
\end{abstract}

Keywords: urban forests, emissions and removal of gases, neutralization, rural and urban balance. 


\section{INTRODUÇÃO}

Em 2009, o Brasil firmou um compromisso, voluntário, de redução das emissões de Gases de Efeito Estufa (GEE), entre $36,1 \%$ e $38,9 \%$ até o ano de 2020 (Política Nacional de Mudanças Climáticas - PNMC, Lei no 12.187/2009) (Brasil, 2009). Com esta Política, introduziu-se a previsão de utilização de instrumentos financeiros e econômicos para promover ações de mitigação e adaptação às mudanças do clima.

O inventário de GEE é um destes instrumentos e tem sido adotado por estados brasileiros como Minas Gerais (2010), São Paulo (2009) e Rio de Janeiro (2010) (Decreto Estadual 45.229/2009, Lei n ${ }^{\circ}$ 13.798/2009 e Lei no 5.690/2010, respectivamente).

Conjuntamente com os inventários de GEE, outras ações de mitigação tem sido propostas, como a neutralização de GEE, que baseia-se na compensação das emissões oriundas de determinada(s) atividade(s) através de iniciativas de redução e/ou remoção como reflorestamento, conservação de áreas verdes ou compra de créditos no mercado de carbono.

A neutralização de GEE tem sido muito empregada por diversos segmentos da economia, sendo que, atualmente, eventos, produtos e festivais nacionais e internacionais tiveram suas emissões neutralizadas como a Copa do Mundo de 2006 na Alemanha e de 2010 na África do Sul (Green goal), os Jogos Pan-Americanos na cidade do Rio de Janeiro em 2006, a Copa do Mundo do Brasil em 2014, dentre outros.

Os órgãos governamentais também têm adotado ações de neutralização de suas emissões. A portaria nº 06/2007 da Secretaria Municipal de Meio Ambiente e do Verde de São Paulo (2007), por exemplo, ressalta que os eventos realizados nos parques municipais são obrigados a compensarem suas emissões de carbono com o plantio de árvores pela cidade, além de ter que realizar o manejo adequado dos resíduos gerados pelos eventos. Soma-se a isso, outras ações de redução de emissões de GEE na área rural, como o Programa Agricultura de Baixo Carbono (ABC) instituído pelo Governo Federal e demais iniciativas de pagamento por serviços ambientais.
Apesar de escassas em universidades brasileiras, tais iniciativas já vêm sendo incorporadas por algumas universidades no mundo. Segundo Rives (2011) nos últimos quatro anos, 674 universidades e faculdades americanas têm como meta tornaremse neutras para o clima, ou seja, estão propondo ações de redução de emissão de dióxido de carbono e de outros gases causadores da elevação das temperaturas globais. Ainda de acordo com a autora, destas universidades, 535 apresentaram inventários de emissão de gases de efeito estufa e 320 elaboraram planos com detalhes de como e quando atingirão as metas de emissão nula.

Desta forma, é cada vez maior a exigência para que instituições, organizações e prefeituras se adequem a um mercado direcionado às questões ambientais e as áreas verdes urbanas surgem como espaços potenciais para projetos de compensação de emissões de GEE.

Neste sentido, com o presente estudo, objetivouse realizar o balanço das emissões e remoções de GEE do campus-sede da Universidade Federal de Viçosa (UFV), comparando a emissão de GEE do ano-base adotado (outubro de 2010 a outubro de 2011) e o incremento de carbono pelos sumidouros da universidade.

\section{MATERIAL E MÉTODOS}

\subsection{Descrição do local de estudo}

O campus-sede da Universidade Federal de Viçosa (UFV) está inserido no município de Viçosa, na Zona da Mata Mineira, entre as coordenadas geográficas $42^{\circ} 52^{\prime} \mathrm{O}$ e $42^{\circ} 50^{\prime} \mathrm{O}$ de longitude e $20^{\circ} 44^{\prime} \mathrm{S}$ e $20^{\circ} 47^{\prime} \mathrm{S}$ de latitude, totalizando uma área de 1.359 hectares (Portes et al., 2009). Predominam na região solos do tipo Latossolo Vermelho e Amarelo álico nos topos de morro e Podzólico Vermelho-Amarelo câmbico nos terraços, em relevo caracterizado por colinas em forma de espigões, bastante seccionadas pela rede de drenagem natural e altitudes variando de 650 a $800 \mathrm{~m}$ (Arruda et al., 1999; Meira-Neto \& Martins, 2002). 


\subsection{Quantificação das emissões de GEE}

A coleta dos dados de emissão de GEE e os cálculos foram feitos de acordo com GHG Protocol (2013), IPCC (2006), e informações coletadas em órgãos administrativos e departamentos da universidade. O estudo foi desenvolvido durante o período de outubro de 2010 a outubro de 2011, sendo considerado este o ano-base do inventário. As emissões advindas do setor de energia (elétrica, biomassa e Gás Liquefeito de Petróleo - GLP), transporte, resíduos (sólido e efluente) e pecuária foram consideradas.

As emissões de dióxido de carbono resultantes da combustão de biomassa são consideradas neutras e não foram contabilizadas no balanço final, pois o $\mathrm{CO}_{2}$ liberado na queima de biomassa é equivalente ao $\mathrm{CO}_{2}$ retirado da atmosfera pela fotossíntese das plantas durante seu período de vida.

Os principais gases como metano e óxido nitroso, foram convertidos para uma unidade comum, $\mathrm{CO}_{2 \text { eq. }}$ (dióxido de carbono equivalente), a partir da multiplicação do montante de cada gás pelo seu respectivo PAG (Potencial de Aquecimento Global); seguindo as recomendações do IPCC (2006) (Equação 1).

$\mathrm{E}_{\text {CO2eq. }}=\mathrm{E}_{\mathrm{i}}{ }^{*} \mathrm{PAG}_{\mathrm{i}}$

onde: $\mathrm{E}_{\mathrm{CO} 2 \mathrm{eq}}=$ emissões totais de dióxido de carbono equivalente, em toneladas; $\mathrm{E}_{\mathrm{i}}=$ emissão do gás de efeito estufa i, em toneladas; $\mathrm{PAG}_{\mathrm{i}}=$ potencial de aquecimento global do gás de efeito estufa i; ${ }_{\mathrm{i}}=$ dióxido de carbono $\left(\mathrm{CO}_{2}\right)$, metano $\left(\mathrm{CH}_{4}\right)$, óxido nitroso $\left(\mathrm{N}_{2} \mathrm{O}\right)$. De acordo com o IPCC (2006), o PAG do $\mathrm{CO}_{2=} 1 ; \mathrm{CH}_{4=} 21$ e $\mathrm{N}_{2} \mathrm{O}=310 \mathrm{em}$ um horizonte de tempo de 100 anos.

\subsection{Quantificação de carbono florestal}

Quantificou-se o carbono presente na arborização do campus-sede da UFV a partir dos dados de cubagem rigorosa em pé dos indivíduos arbóreos, de densidade básica e do teor de carbono adotado. Com base nos registros de idade de plantio das árvores do campus, obteve-se o incremento médio anual em carbono para as espécies avaliadas nas vias e arboretos da universidade, conforme metodologia apresentada por Soares et al. (2006) e Campos \& Leite (2009).

A UFV é delimitada por vasta cobertura florestal. As coberturas florestais nativas são classificadas como Floresta Estacional Semidecidual Montana, segundo o Instituto Brasileiro de Geografia e Estatística - IBGE (1992) e as áreas de reflorestamento com espécies exóticas são formadas, em sua grande maioria, com Eucalyptus spp. (Tabela 1).

Deste modo, estimou-se o Incremento Médio Anual de Carbono (IMAC) das áreas de floresta, capoeira, reflorestamento e mata ciliar presentes no campus-sede da UFV. Para isto, buscaramse trabalhos realizados no próprio campus, no município e também na mesma tipologia florestal.

As pastagens localizadas no campus-sede da UFV, em sua maioria Melinis minutiflora (Miranda Neto et al., 2010), apesar de também fixarem o dióxido de carbono atmosférico através da fotossíntese, não foram computadas como sumidouros, pois as mesmas são consideradas como linha de base em projetos de compensação de carbono, já que entende-se que a ocorrência de pastagens, muitas destas abandonadas, é cenário comum no país e que medidas compensatórias devem ser adicionais às práticas vigentes, como por exemplo, o reflorestamento.

As áreas com agricultura também foram excluídas, pois a biomassa estocada nos plantios, é exportada do local posteriormente, através das colheitas realizadas e reformas no plantio, tornando o balanço das emissões e remoções de dióxido de carbono nulo.

Tabela 1. Classes de uso do solo, suas respectivas áreas (ha) e porcentagem de ocupação em estudo realizado no campus-sede da UFV.

Table 1. Land-use classes, their areas (ha) and percent of occupation at main campus of UFV.

\begin{tabular}{|ccc|}
\hline Uso do solo & Área (ha) & Ocupação (\%) \\
\hline Pastagem & 620,24 & 45,71 \\
\hline Floresta & 270,43 & 19,93 \\
\hline Capoeira & 175,19 & 12,92 \\
\hline Infraestrutura & 127,63 & 9,41 \\
\hline Agricultura & 83,83 & 6,17 \\
\hline Reflorestamento & 59,88 & 4,41 \\
\hline Mata ciliar & 19,65 & 1,45 \\
\hline Total & 1.359 & 100 \\
\hline
\end{tabular}

Fonte: Portes et al. (2009). 


\subsection{Cálculo do balanço de emissões de GEE}

Como a pecuária é uma atividade de cunho rural e sabendo que a UFV possui áreas de florestas que compõem sua Área de Preservação Permanente (APP) e Área de Reserva Legal (ARL) (Lei no.4771/65) (Brasil, 1989), traçou-se um balanço das emissões de GEE, denominado aqui como rural, comparando as emissões da pecuária e o incremento médio anual de carbono das florestas da UFV.

As demais emissões de GEE foram comparadas ao incremento médio anual de carbono da arborização do campus, gerando o balanço urbano de emissões e remoções de GEE. Por fim, obteve-se o balanço geral das emissões e remoções de GEE da UFV a partir da diferença entre a taxa anual de fixação de carbono dos sumidouros avaliados e a emissão total de $\mathrm{CO}_{\text {zeq. }}$ produzida no campus durante o ano-base estipulado.

Assim como calculado para as emissões de GEE, os valores de incremento de carbono foram convertidos para $\mathrm{CO}_{\text {2eq. }}$ através da multiplicação pelo fator 3,67, que corresponde a massa específica do dióxido de carbono (44) sobre a massa específica do elemento carbono (12) (IPCC, 2006) (Equação 2).

$\mathrm{tCO}_{\text {2eq. }}=\left(C * \frac{44}{12}\right) / 1000$

onde: $\mathrm{tCO}_{2 \text { eq. }}=$ dióxido de carbono equivalente, em toneladas; $\mathrm{C}=$ teor de carbono, $\mathrm{em} \mathrm{kg;} \mathrm{44/12} \mathrm{=} \mathrm{massa}$ específica do dióxido de carbono (44) sobre a massa específica do elemento carbono (12).

\section{RESULTADOS E DISCUSSÃO}

\subsection{Balanço de emissões e remoções de GEE em áreas urbanas}

As árvores presentes no campus-sede da UFV apresentaram um Incremento Médio Anual de Carbono (IMAC) variando entre 3,87 e 17,61 $\mathrm{kgC}$ indivíduo $^{-1}$ ano $^{-1}$ e um valor médio entre os indivíduos de $7,79 \mathrm{kgC}$ indivíduo ${ }^{-1}$ ano $^{-1}$. Ao se contabilizar a copa e a raiz das árvores, obteve-se um IMAC de 9,30 kgC indivíduo ${ }^{-1}$ ano $^{-1}$. Assim, se extrapolado para todos os indivíduos avaliados, apresentaria uma taxa de $125,70 \mathrm{tCO}_{\text {2eq. }}$ ano ${ }^{-1}$.

O total das emissões de GEE do campus-sede da UFV foi igual a $2.962,54 \mathrm{tCO}_{\text {2eq. }}$ ano ${ }^{-1}$, se não for incluída a pecuária. Deste modo, nota-se que a arborização do campus contribuiu com a mitigação de apenas $4,24 \%$ do valor total.

Traçado um paralelo com uma área de floresta natural em estágio avançado de regeneração de mesmo tamanho que a encontrada para as árvores urbanas no campus-sede (15,47 ha, Tabela 2) e incremento médio de $1,5 \mathrm{tC} \mathrm{ha}^{-1}$ ano $^{-1}$ apresentado no estudo de Amaro (2010) e também similar a outros trabalhos desenvolvidos para as florestas presentes no campus universitário, observa-se que a taxa de fixação de carbono total obtida, 23,20 tC $\mathrm{ano}^{-1}$, compensa somente $2,87 \%$ das emissões urbanas do campus. Portanto, nota-se que o valor encontrado é menor que o obtido para a arborização.

Desta maneira, as árvores do campus apresentam um incremento médio de carbono superior ao de uma floresta madura, pois esta já se encontra próxima de seu clímax de desenvolvimento e também seus indivíduos sofrem maior competição por recursos naturais entre si. No entanto, para isto, as árvores urbanas necessitam de áreas maiores para um melhor desenvolvimento.

Se fosse possível compensar o restante destas emissões de GEE da UFV sem a pecuária, com árvores urbanas e mantendo a mesma taxa anual de emissão, seria necessário, por exemplo, o plantio de 16.624 árvores por ano adotando um período de

Tabela 2. Incremento médio anual de carbono e área ocupada por cada classe de vegetação no campus-sede da UFV. Table 2. Annual mean carbon increase and area occupied by each vegetation class on main campus of UFV.

\begin{tabular}{ccccc} 
Classe & Incremento $\left(\mathbf{t C O}_{\mathbf{2 e q}} \mathbf{a n o}^{-1}\right)$ & Incremento (\%) & Área (ha) & Área (\%) \\
\hline arborização do campus* & 125,70 & 2,37 & 15,47 & 2,86 \\
capoeira & $1.285,89$ & 24,23 & 175,19 & 32,40 \\
floresta & $1.596,89$ & 30,09 & 290,08 & 53,66 \\
reflorestamento & $2.298,68$ & 43,31 & 59,88 & 11,08 \\
\hline Total & $5.307,16$ & 100 & 540,62 & 100 \\
\hline
\end{tabular}

*Totalizado parte aérea e raiz. 
estocagem de 5 anos ou 2.771 indivíduos traçando um horizonte de 30 anos. Observa-se, portanto, que o número de árvores necessárias para compensar as emissões de GEE anuais da UFV é bem expressivo, requerendo investimentos e principalmente área disponível. Isto pode ser exemplificado com o estudo de Campos (2013) na Zona da Mata mineira. O autor obteve um custo total igual a $\mathrm{R} \$ 4.920,26 \mathrm{ha}^{-1}$ para estabelecimento de um plantio de espécies nativas, sob espaçamento de $3 \times 2 \mathrm{~m}$ entre as plantas, no sistema quincôncio. Caso seja extrapolado para este estudo, o custo total (plantio + manutenção) seria de $\mathrm{R} \$ 49,076.64$.

Os espaços urbanos, em sua grande maioria, sofrem com a falta de planejamento e não possuem áreas disponíveis para uma arborização adequada nas vias públicas e praças. Deste modo, o plantio de um número elevado de árvores para compensar as emissões de GEE de um município pode se tornar uma tarefa de difícil realização.

A cidade conhecida como a capital verde do Brasil, Goiânia, é um exemplo raro de planejamento arbóreo no Brasil. A cidade possui, em vias públicas, cerca de 950.000 árvores pertencentes a 328 espécies diferentes. Há ainda 16 parques e 401 praças, gerando um Índice de Área Verde (IAV) de $94 \mathrm{~m}^{2}$ habitante ${ }^{-1}$ e, em média, 0,79 árvores habitante ${ }^{-1}$ (AMMA, 2013).

Adotando-se o mesmo incremento de carbono obtido neste estudo para as árvores urbanas de Goiânia, pode-se estimar que as mesmas podem compensar, todo ano, cerca de $27.160 \mathrm{tCO}_{2 \mathrm{eq}}$ das emissões totais da cidade; valor que pode amortizar parte significativa das emissões de GEE do município.

Ao analisar as emissões de GEE por fonte, nota-se que as árvores urbanas contribuem com a compensação de toda a emissão anual de $\mathrm{CO}_{2 \mathrm{eq}}$ da queima de Gás Liquefeito de Petróleo (GLP) e de biomassa que abastece as caldeiras da universidade $\left(47,38 \mathrm{tCO}_{2 \mathrm{eq}}\right)$.

Além disso, a arborização do campus compensa 13,54\% das emissões oriundas da combustão móvel, sendo que este valor poderia ser ainda maior, chegando a $27,46 \%$, se houvesse a substituição do consumo de gasolina por etanol nos veículos da universidade.

\subsection{Balanço de emissões e remoções de GEE em áreas rurais}

A UFV possui 290,08 ha de florestas naturais, sendo que $6,7 \%$ deste valor refere-se as matas ciliares (Tabela 1) (Portes et al., 2009). Grande parte destas vegetações é caracterizada como florestas secundárias, ou seja, já tiveram algum tipo de intervenção humana.

Diversos estudos já foram conduzidos nas áreas florestadas do campus-sede da UFV, dentre eles o desenvolvido por Amaro (2010) que, estudando um fragmento de Floresta Estacional Semidecidual de 17 hectares em estágio avançado de sucessão, estimou um estoque médio total (parte aérea e raiz) de 101,7 tC ha ${ }^{-1}$ e incremento médio de $1,5 \mathrm{tC} \mathrm{ha}^{-1} \mathrm{ano}^{-1}$. Valor similar ao encontrado por Boina (2008). Esta autora, avaliando um fragmento de Floresta Estacional Semidecidual em estágio médio de sucessão no Vale do Rio Doce, (MG), estimou uma taxa de fixação média de carbono de 1,34 $\mathrm{t} \mathrm{ha}^{-1} \mathrm{ano}^{-1}$. Em um estudo desenvolvido por Ribeiro et al. (2009) em uma floresta madura (Floresta Estacional Semidecidual) com cerca de 80 anos de idade em Viçosa, MG, os autores obtiveram um estoque de carbono igual a $83,34 \mathrm{tC} \mathrm{ha}^{-1}$.

Desta maneira, levando-se em consideração que as florestas presentes na UFV estão, em sua maioria, em estágios médio e avançado de regeneração e adotando-se o mesmo incremento de 1,5 $\mathrm{tC} \mathrm{ha}^{-1}$ ano${ }^{1}$ apresentado no estudo de Amaro (2010) e também similar a outros trabalhos desenvolvidos para as florestas presentes no campus universitário, o valor total será de 435,12 tC ano $^{-1}$.

Por outro lado, cerca de 175 ha do campus da UFV são compostos por capoeira (Tabela 1). No estudo desenvolvido por Silva (2007a) em Manaus, foi observado um incremento médio de biomassa acima do solo para duas áreas de capoeira aos 14 e 23 anos de idade, de 10,8 e 10,6 $\mathrm{t} \mathrm{ha}^{-1}$ ano $^{-1}$, respectivamente, perfazendo quantidades semelhantes de $C(5,2$ e 5,0 tC ha- ano $^{-1}$ ), nesta ordem.

Áreas de capoeira localizadas na Amazônia Central apresentaram 2,0 tC ha ${ }^{-1} \mathrm{ano}^{-1}$ (Salomão, 1994). Deste modo, como não se conhece o estado de conservação das capoeiras do campus-sede da UFV e baseado nos estudos citados, adotou-se, de 
forma conservadora, um incremento de 2,0 tC $\mathrm{ha}^{-1}$ ano $^{-1}$ para estas áreas. Assim, o incremento total de carbono para as capoeiras presentes na universidade foi de $350,38 \mathrm{t} \mathrm{ano}^{-1}$.

As plantações de Eucalyptus spp., Tectona grandis e Pinus spp. podem fixar entre 2,7 e 9,6 tC há-1 ano ${ }^{-1}$, entretanto, estes valores podem ser até mais elevados (Brown et al., 1989). Em povoamentos de eucalipto no Espírito Santo, Reis et al. (1994), por exemplo, obtiveram um incremento médio de carbono, considerando somente a parte aérea, de 10,32 $\mathrm{t} \mathrm{ha}^{-1}$ ano $^{-1}$ aos 7 anos de idade. Já Paixão et al. (2004) estudando plantios de eucalipto aos 6 anos de idade em Viçosa, MG, quantificaram para a parte aérea, raiz e serapilheira, $11,85 \mathrm{tC} \mathrm{ha}^{-1} \mathrm{ano}^{-1}$.

Silva (2007b) avaliando plantios de eucalipto em três classes de produtividade no município de Guanhães (MG), obteve, em média, um incremento de 10,09 tC ha-1 ano $^{-1}$.

Levando-se em consideração, portanto, os estudos relatados e sabendo que a maior parte das áreas de reflorestamento no campus-sede da UFV é formada por plantios de eucalipto, adotou-se para estas áreas um incremento médio de carbono de $10,46 \mathrm{t} \mathrm{ha}^{-1} \mathrm{ano}^{-1}$. Logo, as áreas de reflorestamento da UFV fixam em torno de 626,34 tC ano ${ }^{-1}$.

Assim, apesar de 5 vezes menor que as áreas de floresta, as áreas de reflorestamento apresentaram uma taxa de fixação anual de carbono 1,4 vezes maior, por possuírem um alto valor de incremento.

Desta maneira, ao todo, as áreas de floresta, capoeira e reflorestamento presentes no campussede da UFV apresentaram uma taxa de fixação anual de carbono de 5.181,47 $\mathrm{tCO}_{2 \text { eq. }}$, valor superior à emissão de GEE pela pecuária $\left(3.071,64 \mathrm{tCO}_{2 \text { eq. }}\right)$. Para que neutralizasse apenas as emissões oriundas da pecuária, seria necessária uma área de 311,31 ha, cerca de $2 / 3$ da área total dos sumidouros.

Segundo estudo de Portes et al. (2009), 354,89 ha ou $26,11 \%$ da área total da universidade são Áreas de Preservação Permanente (APP) que, de acordo, com a Resolução nº 303/2002 do CONAMA (Brasil, 2002), são instrumentos de relevante interesse ambiental. Ainda segundo os autores, parte desta APP se encontra ocupada pela infraestrutura do campus.
O Código Florestal (Lei $\mathrm{n}^{\circ} 4.771 / 65$ ) afirma que $20 \%$ da área total do imóvel, no localizado no bioma Mata Atlântica, excluindo-se as APPs, deve ser delimitada como Áreas de Reserva Legal (ARL) (Brasil, 1989). Deste modo, sabendo que a área total do campus-sede da UFV é de 1.359 ha e as APPs somam 354,89 ha, a ARL corresponde a 200,80 ha. Ao somar as APPs e a ARL, obtêm-se 555,69 ha, valor superior às áreas de floresta, capoeira e reflorestamento da universidade juntas (Tabela 1).

Assim, as APPs e ARL, com vegetação, da UFV compensam toda a emissão de GEE oriunda da pecuária. Entretanto, se esta área total fosse igual à exigida por lei, o potencial de compensação de GEE da universidade poderia ser ainda maior, mostrando a importância destas áreas também na mitigação do efeito estufa.

O solo, principal reservatório terrestre de carbono, compreende aproximadamente o dobro da quantidade de carbono atmosférico e da biomassa vegetal (Bruce et al., 1999), no entanto, o solo apresenta baixo incremento de carbono. Ferez (2010) comparando o estoque de carbono orgânico do solo de uma Floresta Estacional Semidecidual e um plantio de restauração, concluiu que não havia diferença significativa entre as áreas. Além disso, segundo a autora, o estoque de carbono na camada de 0-30 $\mathrm{cm}$ de profundidade do solo na área de restauração antes do plantio era de 30,9 $\pm 5,9 \mathrm{tC} \mathrm{ha}^{-1}$,

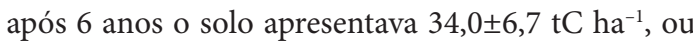
seja, um incremento de cerca de $0,5 \pm 0,1 \mathrm{tC} \mathrm{ha}^{-1} \mathrm{ano}^{-1}$.

Segundo Bernoux et al. (2002) a camada de 0-30 cm dos solos de uma Floresta Estacional Semidecidual contém em média 41,7 tC ha ${ }^{-1}$, valor maior ao encontrado por Ferez (2010). Logo, o estoque de carbono no solo apresenta grande variação espacial e baixa variação temporal (Smith, 2004).

Assim, o potencial de estocagem de carbono no solo dos sumidouros da universidade pode ser mais elevado. Como a assimilação de carbono no solo é dependente principalmente das características físicoquímicas do solo, de fatores edafoclimáticos e da prática de manejo (Ferez, 2010), fica difícil estimar o potencial de estocagem de carbono para todas as áreas, sendo excluído das estimativas. 


\subsection{Balanço geral (urbano e rural)}

Ao final, somando-se o incremento de carbono de todos os sumidouros, obteve-se um total de $5.307,16 \mathrm{tCO}_{2 \text { eq. }}$, sendo que $43,31 \%$ deste valor é referente às áreas de reflorestamento (Tabela 2).

A emissão total de GEE da UFV foi de 6.034,18 $\mathrm{tCO}_{\text {2eq. }}$ durante o ano-base adotado, sendo que a principal fonte emissora foi a pecuária $(50,90 \%)$, seguida dos resíduos sólidos (16,57\%) e efluentes $(12,44 \%)$, as demais fontes somaram $(20,09 \%)$.

Apesar do campus-sede da UFV possuir uma grande extensão de sumidouros, que representam 39,84\% de sua área total, a emissão de GEE da UFV foi ainda um pouco superior a taxa de fixação média anual de carbono. Portanto, o balanço geral das emissões e remoções de GEE do campus-sede da UFV foi negativo (Figura 1).

Observa-se, deste modo, que as áreas de vegetação presentes no campus-sede da UFV não neutralizam toda a emissão de GEE gerada pelas atividades da universidade. Entretanto, estas áreas contribuem para a mitigação das emissões geradas e, consequentemente, para a atenuação das mudanças climáticas.

Partindo do pressuposto que a UFV desejasse compensar o restante de suas emissões com o plantio de árvores no próprio campus, a fim de tornar seu balanço geral de emissões e remoções de GEE nulo

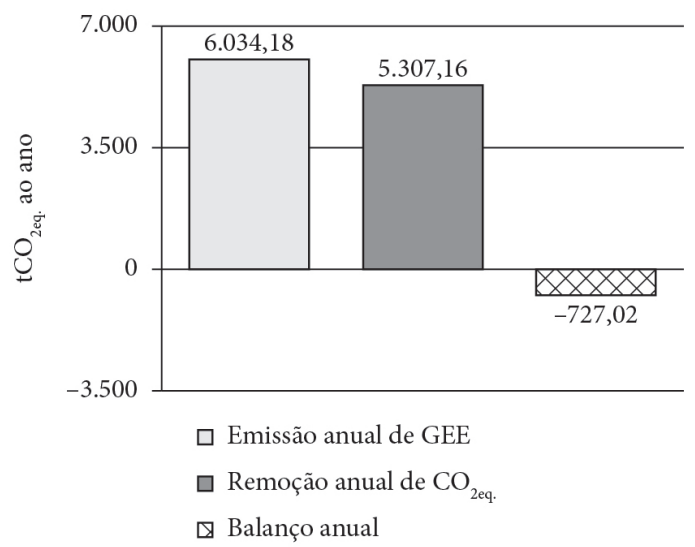

Figura 1. Balanço geral das emissões e remoções de GEE do campus-sede da UFV.

Figure 1. Global balance of GHG emissions and removals at UFV main campus. e/ou positivo, levou-se em consideração neste estudo duas possibilidades: a recomposição vegetal com espécies nativas ou o plantio de árvores nas vias urbanas do campus.

Segundo Melo \& Durigan (2006), plantios com espécies nativas na região de São Paulo, apresentaram um incremento médio de $5,2 \mathrm{tC} \mathrm{ha}{ }^{-1} \mathrm{ano}^{-1}$. Já Preiskorn (2011) obteve uma taxa média de fixação de carbono de 4,6 tC ha ${ }^{-1}$ ano $^{-1}$ para plantios de restauração na margem da Rodovia dos Bandeirantes, São Paulo. Plantios de restauração localizados em áreas de Floresta Estacional Semidecidual em cinco localidades na região sudoeste do estado de São Paulo foram avaliados por Miranda (2008) que obteve valores de incremento médio de carbono variando de 4,8 a $5,6 \mathrm{t} \mathrm{ha}^{-1} \mathrm{ano}^{-1}$.

Deste modo, caso a universidade optasse como forma de compensação o reflorestamento com espécies nativas e adotando um valor médio de 5,0 tC ha ${ }^{-1}$ ano $^{-1}$, a UFV necessitaria plantar 39,62 ha com espécies nativas para neutralizar todas as suas emissões de GEE anuais. Valor este diferente do encontrado por Santos et al. (2010) que constataram que para neutralizar as $218 \mathrm{tCO}_{\text {2eq. }}$ geradas no campus da Universidade Federal de Tocantins seria necessário o plantio de 1702 mudas nativas do Cerradão em 1,02 ha, mostrando que o montante de emissões, bem como as características da vegetação, local e plano de manejo adotado podem alterar os resultados obtidos.

Se a compensação do restante das emissões de GEE da universidade fosse realizada com o plantio de árvores nas vias de acesso e estacionamentos do campus-sede, deveria-se plantar cerca de 21.300 árvores distribuídas em uma área total de 41,83 ha.

Nota-se, portanto, que a estocagem de carbono pela arborização pode ser uma proposta interessante para a compensação de GEE, desde que haja espaço, planejamento e monitoramento adequado para isto.

Uma ação interessante para a compensação das emissões a partir do plantio de árvores é envolver estudantes, funcionários da instituição e demais membros da sociedade. A universidade possui atualmente 13.931 pessoas, sendo que 10.941 são estudantes matriculados, 2.042 são servidores, 948 são docentes, gerando uma emissão per capita de 212,66 $\mathrm{kgCO}_{\text {2eq. }}$ ano $^{-1}$. Desta maneira, considerando 
que um curso de graduação na universidade tem duração em torno de 5 anos, cada estudante matriculado deveria plantar cerca de 7 árvores para compensar suas emissões neste tempo ou 2 árvores levando em consideração um período de crescimento da árvore de 20 anos.

No caso de um docente ou servidor da universidade que desejasse compensar todas as suas emissões num período de 30 anos, correspondente ao seu tempo de serviço, cada trabalhador deveria plantar 10 árvores adotando um período de crescimento arbóreo de 20 anos.

Outra iniciativa complementar que pode contribuir para a compensação total das emissões do campus é a compra de créditos de carbono no mercado de carbono, Quioto e Voluntário (Valdetaro et al., 2011). Assim, instituições como a UFV e qualquer outra organização ou órgão, assim como prefeituras podem adquirir créditos de carbono de projetos de redução/remoção de GEE, de forma a abater o restante de emissões não compensadas pelas suas áreas verdes.

Desta forma, a administração pública deve vislumbrar nas áreas verdes urbanas não somente os benefícios ambientais e sociais já conhecidos, mas também um viés econômico, seja através de projetos de comercialização de créditos de carbono, como também iniciativas voluntárias de compensação/ neutralização das emissões de GEE.

Paralelo a isso, é importante frisar a necessidade da adoção de medidas de redução de emissões de GEE, como substituição da gasolina utilizada pela frota de veículos por etanol, quando possível; diminuição da geração de lixo, e aumento da coleta seletiva e da reciclagem; melhorias no manejo dos animais; dentre outros.

\section{CONCLUSÕES}

Verificou-se que os sumidouros presentes no campus fixaram 5.307,16 $\mathrm{tCO}_{2 \text { eq. }}$ e compensaram $87,95 \%$ das emissões totais $(6.034,18$ toneladas de $\mathrm{CO}_{\text {2eq. }}$ ) da universidade. Deste modo, o balanço geral obtido das emissões e remoções de GEE da UFV foi deficitário No entanto, as áreas verdes urbanas apresentaram um grande potencial de fixação de carbono. O manejo florestal atrelado a ações de pesquisa e extensão podem contribuir para o aumento do estoque de carbono.

A compensação de carbono a partir de ações de neutralização de GEE, seja com o reflorestamento ou com atividades de conservação florestal, é uma prática interessante de atenuação do efeito estufa. Entretanto, não deve restringir-se a esta iniciativa. Ações de redução das emissões de GEE são também importantes e devem ser trabalhadas concomitantemente. Ademais, as universidades tem um papel fundamental não somente no campo científico, mas também na vanguarda das ações.

\section{AGRADECIMENTOS}

Ao Conselho Nacional de Desenvolvimento Científico e Tecnológico - CNPq, e à Fundação de Amparo à Pesquisa de Minas Gerais - FAPEMIG, pelo apoio financeiro e concessão de Bolsa.

\section{STATUS DA SUBMISSÃO}

Recebido: 04 set., 2013

Aceito: 13 fev., 2014

Publicado: 30 jun., 2014

\section{AUTOR(ES) PARA CORRESPONDÊNCIA}

\section{Daniel Brianezi}

Departamento de Engenharia Florestal, Universidade Federal de Viçosa - UFV, CEP 36570-000, Viçosa, MG, Brasil

e-mail: daniel.floresta@yahoo.com.br

\section{APOIO FINANCEIRO}

Conselho Nacional de Desenvolvimento Científico e Tecnológico - CNPq e Fundação de Amparo à Pesquisa de Minas Gerais - FAPEMIG.

\section{REFERENNCIAS}

Arruda PRR, Silva E, Couto L. Problemática ambiental da Bacia Hidrográfica do Ribeirão São Bartolomeu, Viçosa-MG. Revista Árvore, Viçosa, 1999, 23: 49-53.

Amaro MA. Quantificação do estoque volumétrico, de biomassa e de carbono em uma Floresta Estacional Semidecidual no município de Viçosa, MG [tese].Viçosa: 
Departamento de Engenharia Florestal, Universidade Federal de Viçosa; 2010.

Agência Municipal do Meio Ambiente - AMMA. Plano Diretor de Arborização Urbana de Goiânia [on line]. [cited in 2013]. Available from: http//:www.goiania. go.gov.br/download/amma/relatório_Plano_Diretor. pdf.

Bernoux M, Conceição M, Carvalho S, Volkoff B, Cerri CC. Brazil's Soil Carbon Stocks. Soil Science Society of America Journal, 2002; 66: 888-896. http://dx.doi. org/10.2136/sssaj2002.0888

Boina A. Quantificação de estoques de biomassa e de carbono em floresta estacional semidecidual, Vale do Rio Doce, Minas Gerais [Tese].Viçosa: Departamento de Engenharia Florestal, Universidade Federal de Viçosa; 2008.

Brasil. Lei no 7.803 , de 18 de setembro de 1989, Altera a redação da Lei $n^{\circ} 4.771$, de 15 de setembro de 1965 , e revoga as Leis $\mathrm{n}^{\circ} 6.535$, de 15 de junho de 1978, e 7.511, de 7 de julho de 1986. Diário Oficial da República Federativa do Brasil, Brasília, DF (1989 set 18).

Brasil. Lei no 12.187 de 29 de dezembro de 2009. Institui a Política Nacional sobre Mudança do Clima - PNMC e dá outras providências. Diário Oficial da República Federativa do Brasil, Brasília, DF (2009 dez 29).

Brasil. Resolução do CONAMA no 303, de 20 de março de 2002, Dispõe sobre os parâmetros, definições e limites de Áreas de Preservação Permanente. Diário Oficial da República Federativa do Brasil, Brasília, DF (2002 mar).

Brown S, Gillespie AJR, Lugo AE. Biomass estimation methods for tropical forests with applications to forest inventory data. Forest Science 1989; 35: 881-902.

Bruce JP, Frome M, Haites E, Janzen H, Lal R, Paustian K. Carbon sequestration in soils. Journal Soil, Water and Conservation 1999; 54: 382-389.

Campos RA. Análise dos custos de recuperação de áreas de preservação permanente em quatro municípios da bacia do rio Xopotó [monografia]. Viçosa: Universidade Federal de Viçosa; 2013.

Campos JCC, Leite HG. Mensuração florestal - Perguntas e Respostas. 3. ed. Viçosa: Editora UFV; 2009.

Ferez APC. Efeito de práticas silviculturais sobre as taxas iniciais de sequestro de carbono em plantios de restauração da Mata Atlântica. [dissertação]. Piracicaba: Escola Superior de Agricultura "Luiz de Queiroz", Universidade de São Paulo; 2010.

GHG Protocol Brasil. Especificações do Programa Brasileiro GHG Protocol. 75 p. [cited 2013 set. 01]. Available from: http://www.ghgprotocolbrasil.com.br.

Instituto Brasileiro de Geografia e Estatística - IBGE. Manual técnico da vegetação brasileira. Manuais técnicos em geociências número 1. Rio de Janeiro: IBGE; 1992.
Intergovernmental Panel on Climate Change - IPCC. IPCC guidelines for national greenhouse gas inventories: agriculture, forestry and other land use. v. 4. Tokyo: Institute for Global Environmental Strategies, 2006.

Melo ACG, Durigan G. Fixação de carbono em reflorestamentos de matas ciliares no Vale do Paranapanema, SP, Brasil. Scientia Forestalis 2006; 71: 149-154.

Meira-Neto JAA, Martins FR. Composição florística de uma floresta estacional semidecidual montana no município de Viçosa-MG. Revista Árvore, Viçosa 2002; 26(4): 437-446.

Minas Gerais (Estado). Decreto Estadual 45.229, de 04 de dezembro de 2009. Regulamenta medidas do Poder Público do Estado de Minas Gerais referentes ao combate às Mudanças Climáticas e Gestão de Emissões de Gases de Efeito Estufa; p.2; 31 de agosto de 2010.

Miranda DLC. Modelos matemáticos de estoque de biomassa e carbono em áreas de restauração florestal no sudoeste paulista [dissertação]. Curitiba: Departamento de Engenharia Florestal, Universidade Federal do Paraná; 2008.

Miranda Neto A, Kunz SH, Martins SV, Silva KA, Silva DA. Transposição do banco de sementes do solo como metodologia de restauração florestal de pastagem abandonada em Viçosa, MG. Revista Árvore 2010; 34(6): 1035-1043. http://dx.doi.org/10.1590/S010067622010000600009

Paixão FA. Quantificação do estoque de carbono e avaliação econômica de alternativas de uso de um povoamento de eucalipto [dissertação]. Viçosa: Departamento de Engenharia Florestal, Universidade Federal de Viçosa; 2004.

Portes RC, Fernandes Filho EI, Faria ALL, Barbosa AW. Espacialização das restrições ambientais como subsídio ao plano de desenvolvimento físico e ambiental do campus da Universidade Federal de Viçosa - Viçosa. In: Resumos do XIII Simpósio Brasileiro de Geografia Física Aplicada, 2009.

Preiskorn GM. Composição Florística, estrutura e quantificação do estoque de carbono em florestas restauradas com idades diferentes [dissertação]. Piracicaba: Escola Superior de Agricultura "Luiz de Queiroz", Universidade de São Paulo; 2011.

Reis MGF, Reis GG, Valente OF, Fernandes HAC. Sequestro e armazenamento de carbono em florestas nativas e plantadas dos Estados de Minas Gerais e Espírito Santo. In: Seminário emissão $x$ sequestro de $\mathrm{CO}_{2}$ - Uma nova oportunidade de negócios para o Brasil; 1994; Rio de Janeiro. Rio de Janeiro; 1994. p. 155-195.

Ribeiro SC, Jacovine LAG, Soares CPB, Martins SV, Souza AL, Nardelli AMB. Quantificação de biomassa e estimativa de estoque de carbono em uma floresta 
madura no município de Viçosa, Minas Gerais. Revista Árvore Viçosa; 2009. 33(5): 917-926.

Rio de Janeiro (Estado). Lei $n^{\circ} 5.690,14$ de abril de 2010. Institui a política estadual sobre mudança global do clima e desenvolvimento sustentável e dá outras providências. Diário Oficial do Estado do Rio de Janeiro; p. 1.

Rives, K. Universidades americanas correm para cortar emissões de gases de efeito estufa. Missão diplomática dos Estados Unidos - Meio ambiente; 2011 [cited in 2013 jul. 25]. Available from: http//:www.portuguese.brazil. usembassy.gov/pt/estufa.html.

Salomão RP. Estimativas de biomassa e avaliação do estoque de carbono da vegetação de florestas primárias e secundárias de diversas idades (capoeiras) na Amazônia Oriental, município de Peixe-boi, Pará [dissertação]. Universidade Federal do Pará; 1994.

Santos DRR, Picanço AP, Maciel GF, Serra JCV. Estudo de neutralização dos gases de efeito estufa da Universidade Federal de Tocatins - Reitoria e campus universitário de Palmas: Uma forma de mitigação ambiental. Revista Geográfica Acadêmica 2010; 4(2): 29-40.

São Paulo (Estado). Lei no 13.798 , de 09 de novembro de 2009. Institui a Política Estadual de Mudanças Climáticas - PEMC. Diário Oficial do Estado de São Paulo. 10 nov. 2009; 119(209).
São Paulo. Secretaria Municipal do Verde e do Meio Ambiente. Portaria no 6, de 24 de janeiro de 2007. Institui a compensação das emissões de Gases de Efeitos Estufa (GEE) e o manejo adequado dos resíduos gerados pelos eventos realizados nos parques municipais de São Paulo, a saber: shows, concertos, exposições e eventos do gênero, envolvendo a circulação de grande público. Diário Oficial do Estado de São Paulo, São Paulo, (2007 jan.).

Silva RP. Alometria, estoque e dinâmica da biomassa de florestas primárias e secundárias na região de Manaus (AM) [tese]. INPA/UFAM; 2007a.

Silva RF. Projeção do estoque de carbono e análise da geração de créditos em povoamentos de eucalipto [dissertação]. Departamento de Engenharia Florestal, Universidade Federal de Viçosa; 2007b.

Smith P. How long before a change in soil carbon organic can be detected? Global Change Biology. 10:1878-1883, 2004. http://dx.doi.org/10.1111/j.13652486.2004.00854.x

Soares CPB, Paula Neto F, Souza AL. Dendrometria e Inventário Florestal. Viçosa: Editora UFV, 2006. 276 p.

Valdetaro EB, Silva FL, Ribeiro SC, Jacovine LAG. Contribuição dos créditos de carbono na viabilidade econômica dos contratos de fomento florestal no sul da Bahia. Revista Árvore 2011; 35(6): 1307-1317. http:// dx.doi.org/10.1590/S0100-67622011000700017 